\title{
Nitrogen doping of amorphous carbon thin films
}

\author{
J. Schwan, ${ }^{\text {a) }}$ V. Batori, S. Ulrich, and H. Ehrhardt \\ Universität Kaiserlautern, FB Physik, Schrödingerstrasse, 67663 Kaiserslautern, Germany \\ S. R. P. Silva \\ University of Surrey, Electronic and Electrical Engineering, Guildford, Surrey GU2 5XH, England
}

(Received 7 April 1997; accepted for publication 11 May 1998)

\begin{abstract}
Nitrogenated and hydrogenated amorphous carbon $(a-\mathrm{C}: \mathrm{H}: \mathrm{N})$ films have been deposited by a plasma beam source using a gas mixture of $\mathrm{C}_{2} \mathrm{H}_{2}$, Ar and $\mathrm{N}_{2}$. The $\mathrm{Ar} / \mathrm{C}_{2} \mathrm{H}_{2}$ ratio is kept constant at a ratio of 3, with the nitrogen flow allowed to vary. Nonnitrogenated films, with $\mathrm{Ar} / \mathrm{C}_{2} \mathrm{H}_{2}$ ratios of 3 and 6 were also deposited and analyzed before attempting to identify the modifications to the microstructural properties due to nitrogen doping. The nitrogenated and hydrogenated $a$-C $(a-\mathrm{C}: \mathrm{H}: \mathrm{N})$ films deposited in this study reveal interesting properties with regard to their optical gap, electrical conductivity, and mobility of the charge carriers. The optical $E_{04}$ gap passes through a maximum of $2.7 \mathrm{eV}$ as a function of incorporated nitrogen. The electrical conductivity, too, reaches a peak value of $10^{-3}(\Omega \mathrm{cm})^{-1}$ with increasing optical gap and remains constant for higher $\mathrm{N}_{2}$ flows. The electrical conductivity process is thermally activated with activation energies in the range $0.1-0.3 \mathrm{eV}$. This is discussed in terms of the mobility of the charge carriers (determined by Hall measurements) and electronic doping. The defect density (measured by electron spin resonance) is found to decrease with increasing nitrogen incorporation. The films have also been characterized by infrared spectroscopy, photo thermal deflection, and Raman spectroscopy. The microstructure of the deposited $a-\mathrm{C}: \mathrm{H}: \mathrm{N}$ films is discussed in terms of the electronic density of states. (c) 1998 American Institute of Physics. [S0021-8979(98)03616-0]
\end{abstract}

\section{INTRODUCTION}

The enviable physical properties of amorphous hydrogenated carbon $(a-\mathrm{C}: \mathrm{H})$, e.g., low friction coefficient and high hardness, make these films useful material for mechanical applications. Electronic doping of $a-\mathrm{C}: \mathrm{H}$ films has often been discussed. Meyerson and Smith ${ }^{1-3}$ deduced from their experimental results that doping of amorphous hydrogenated carbon is possible. Since then, there has been significant scientific interest in the electrical and optical properties of nitrogenated amorphous carbon films. ${ }^{4}$ The synthesis of the superhard compound $\beta-\mathrm{C}_{3} \mathrm{~N}_{4}$ is another aspect, not discussed in this article, that has motivated research. ${ }^{5}$

Amir and Kalish ${ }^{6}$ and Schwan et al. $^{7}$ found that nitrogenation of $a-\mathrm{C}: \mathrm{H}$ leads to a "graphitization" of amorphous hydrogenated carbon when deposited with a standard plasma enhanced chemical vapor deposition (PECVD) system. They questioned if true electronic doping in PECVD deposited $a-\mathrm{C}: \mathrm{H}$ was occurring or even possible. Recently, a highly $s p^{3}$ bonded form of $a$-C (highly tetrahedral amorphous carbon, ta-C) has been deposited by filtered cathodic vacuum are (FCVA). ${ }^{8}$ They ${ }^{9,10}$ found that these films can be doped controllably by $\mathrm{N}$ and found that the Fermi level of ta-C films can be moved throughout the band gap. Conversely, Ronning et al. ${ }^{11}$ and Hofsäss and Ronning ${ }^{12}$ didn't find doping effects in their mass selected ion beam deposited (MSIB) ta-C (although they did not deposit both $\mathrm{C}$ and $\mathrm{N}$ simultaneously but more as a multilayer structure).

${ }^{a)}$ Author to whom correspondence should be addressed; present address: SAP AG, LOG.DEV.03, Neurott Str. 16, 69190 Walldorf, Germany.
Weiler et al. ${ }^{13}$ reported that it is possible to deposit amorphous hydrogenated carbon films with high $s p^{3}(75 \%)$ and $\mathrm{H}$ contents $(27 \%)$, and stated ${ }^{14}$ that it is possible to dope the ta-C:H films deposited using the plasma beam source (PBS). However, it should be noted that ta-C films ${ }^{15}$ as well as $a$-C films deposited by PBS $^{14}$ possess defect densities as high as $1 \times 10^{20}$ defects $/ \mathrm{cm}^{3}$. These high defect densities underline the difficulties involved in electronically doping these films.

In this work, thin $a-\mathrm{C}: \mathrm{H}$ films have been deposited by a highly ionized plasma beam using a mixture of acetylene and argon as the working gases. By varying the energy of both the acetylene and the argon ions it is possible to minimize the hydrogen content in the films down to 2.5 at. \%. Measurements of the optical gap of the nonnitrogenated films reveal two maxima at about 100 and $200 \mathrm{eV}$ ion energy. Other film properties such as stress, electrical conductivity, defect density as determined by electron spin resonance (ESR or EPR) are also presented. We show that two distinct processes occur in PBS deposition if a gas mixture of argon and acetylene is used as the working gases. Knock on processes of carbon atoms at the surface by $\mathrm{Ar}^{+}$ions of the plasma beam can be observed in addition to impacts of the acetylene ions. Films have been deposited by varying the ion energy and the acetylene to argon ratio of the working gas mixture. The argon ion bombardment at ion energies of about $100 \mathrm{eV}$ is responsible for a dramatic decrease in the hydrogen content down to $2-3$ at. $\%$. This decrease is accompanied by an increase in the energy gap.

Further, we study the properties of nitrogenated $a-\mathrm{C}: \mathrm{H}$ films deposited using the PBS system. We present experi- 
TABLE I. Gas flow into PBS chamber during the deposition of the $a-\mathrm{C}: \mathrm{H}:(\mathrm{N})$ thin films.

\begin{tabular}{ccc}
\hline \hline $\mathrm{C}_{2} \mathrm{H}_{2}[\mathrm{sccm}]$ & $\mathrm{Ar}[\mathrm{sccm}]$ & $\mathrm{N}_{2}[\mathrm{sccm}]$ \\
\hline 1.25 & 3.75 & 0.0 \\
1.25 & 3.75 & 0.05 \\
1.25 & 3.75 & 0.10 \\
1.25 & 3.75 & 0.20 \\
1.25 & 3.75 & 0.30 \\
1.25 & 3.75 & 0.50 \\
1.25 & 3.75 & 0.75 \\
1.25 & 3.75 & 1.00 \\
\hline \hline
\end{tabular}

mental results concerning the optical gap, luminescence, the electrical conductivity, mobility of the charge carrieres, luminescence, ESR and Fourier-transform infrared FTIR spectroscopy.

\section{EXPERIMENT}

The PBS apparatus is similar to that used by Weiler et $a l .{ }^{13}$ in which the structure of the $a-\mathrm{C}: \mathrm{H}$ film is controlled solely by ions. A radio frequency (rf) power of $30 \mathrm{~W}$ at $13.56 \mathrm{MHz}$ is applied via a capacitor and matching network between the ground electrode and the powered electrode. The pumping speed was $1800 \ell$ s given by a turbomolecular pump. The pressure in the plasma chamber remained below $1 \times 10^{-4}$ mbar during deposition. For the experiments without nitrogen two different acetylene/argon ratios of 3 and 6 have been used. For those experiments the ion energy was varied between 80 and $250 \mathrm{eV}$. Ion energy and ion current density have been measured by a Faraday cup using a retarding field probe. Measured ion current densities in our experiments showed a slight variation with the ion energy from 0.13 to $0.2 \mathrm{~mA} / \mathrm{cm}^{2}$. The energy spread of the ion beam was found to be $\Delta E / E<0.1$. The background pressure before each deposition was less than $1 \times 10^{-7}$ mbar. Crystalline silicon and quartz glass substrates have been used and placed in a large copper holder for the deposition. The substrate temperature during deposition was measured to be below $50{ }^{\circ} \mathrm{C}$. For the deposition of nitrogenated $a-\mathrm{C}: \mathrm{H}$ films the $\mathrm{C}_{2} \mathrm{H}_{2}, \mathrm{Ar}$, and $\mathrm{N}_{2}$ flows are given in Table I. The ion energy used for the deposition of the $a-\mathrm{C}: \mathrm{H}: \mathrm{N}$ films is fixed at 105 eV.

The defect density has been determined by electron paramagnetic resonance. A microwave frequency of about 9.3 $\mathrm{GHz}$ and a magnetic field of 3400 Gauss was used with a modulation amplitude of 1 Gauss. The microwave power was below $35 \mu \mathrm{W}$ in order to avoid saturation effects. Conductivity corrections have also been performed to achieve correct defect density values. The total number of defects in the $a-\mathrm{C}: \mathrm{H}$ films were determined by comparison to a diphenylpicrylhydrazyl (DPPH) standard. Measurements of the electrical conductivity were made on a temperature regulated vacuum stand that allows variation between 200 and $600 \mathrm{~K}$.

The films were also characterised using FTIR, Raman, photo thermal deflection (PDS), luminescence spectroscopy, and temperature dependent electrical conductivity. Hall measurements have been performed using the van der Pauw

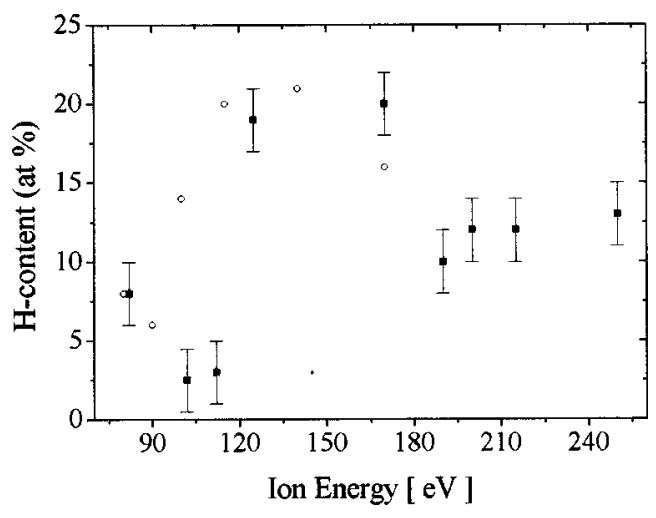

FIG. 1. Hydrogen content of plasma beam deposited $a-\mathrm{C}: \mathrm{H}$ films with working gas mixture containing both acetylene and argon. $\mathrm{Ar} / \mathrm{C}_{2} \mathrm{H}_{2}=3: 1$ (ם), $\mathrm{Ar} / \mathrm{C}_{2} \mathrm{H}_{2}=6: 1$ (O).

method. ${ }^{16}$ The voltage between two contacts has been measured 10000 times to prevent statistical noise errors over a period of two days. This has been performed for each necessary pair of contacts and for the possible magnetic field directions. The influence of the contact areas have been corrected by the method of Chwang, Smith, and Crowell. ${ }^{17}$ For each film at least five mobility measurements have been performed with each measurement being averaged over 10000 separate voltage/current pairs. The magnetic field during the measurement was $\pm 1.4 \mathrm{~T}$. Polycrystalline diamond films with different $\mathrm{B}$ contents were also measured on the same apparatus and found to give the expected Hall mobility and coefficient values. ${ }^{18}$

Further, the elemental composition has been obtained by measuring the $\mathrm{N}$ content by RBS and using the ${ }^{15} \mathrm{~N}(p, \alpha \gamma){ }^{12} \mathrm{C}$ reaction. The $\mathrm{H}$ content has been determined by the ${ }^{15} \mathrm{~N}$ method.

\section{RESULTS}

\section{A. Deposition of a-C:H in an $\mathrm{Ar} / \mathrm{C}_{2} \mathrm{H}_{2}$ atmosphere}

The plasma and the produced ion beam used for the deposition is examined first. The operation with pure acetylene revealed results similar to previous studies in terms of energy distribution and ion current on a PBS. ${ }^{13}$ Surprisingly, the PBS produces ions with roughly the same energy regardless of whether argon or acetylene, or a mixture of both gases, are used. Argon content was measured by Rutherford backscattering. In all the films examined the argon content is found to be constant at approximately 4 at. \%. This was verified by electron-energy-loss spectrostopy (EELS) analysis. Due to the inertness of argon these atoms are unlikely to be be bonded, and must be interstitially trapped. Hydrogen content of the deposited films is shown in Fig. 1 as a function of ion energy, which is equal for both ion species $\mathrm{Ar}^{+}$and $\mathrm{C}_{2} \mathrm{H}_{2}^{+}$. The open circles and the filled boxes represent $\mathrm{Ar} / \mathrm{C}_{2} \mathrm{H}_{2}$ ratios of 6 and 3 , respectively. Compared to the PBS deposited films of Weiler et al., ${ }^{13}$ who determined about 25 at. $\%$ hydrogen in their films without simultaneous argon bombardment, the $\mathrm{H}$ content lies roughly at half their value (12 at. \%) at an ion energy of $200 \mathrm{eV}$. At lower energies than $200 \mathrm{eV}$ the hydrogen content increases at first, but 
TABLE II. Assigned wavelength in the infrared spectrum of $a$-C:H according to Dischler et al. (Ref. 19).

\begin{tabular}{cc}
\hline \hline Wavelength $\left[\mathrm{cm}^{-1}\right]$ & Assigned vibration in IR spectrum \\
\hline 2850 & $s p^{3} \mathrm{CH}_{2}$ (symmetric) \\
2920 & $s p^{3} \mathrm{CH}$ \\
& $s p^{3} \mathrm{CH}_{2}$ (asymmetric) \\
2960 & $s p^{3} \mathrm{CH}_{3}$ (asymmetric) \\
3000 & $s p^{2} \mathrm{CH}$ (aliphatic bond) \\
3045 & $s p^{2} \mathrm{CH}$ (aromatic bond) \\
3060 & $s p^{2} \mathrm{CH}$ (aromatic bond) \\
\hline \hline
\end{tabular}

reaches a minimum at an ion energy of $100 \mathrm{eV}$ where the hydrogen content drops down to $2-3$ at. $\%$ for an $\mathrm{Ar} / \mathrm{C}_{2} \mathrm{H}_{2}$ ratio of 3 and down to $5 \%$ for an $\mathrm{Ar} / \mathrm{C}_{2} \mathrm{H}_{2}$ ratio of 6 . The extreme low hydrogen content was not found when depositing at the same ion energies using pure acetylene, where 24 at. \% was measured similar to those obtained by Weiler. The shift in the minimum in hydrogen content for the higher Ar/Acetylene ratio being at a lower energy $(90 \mathrm{eV}$, shown in Fig. 1) must be related to processes initiated by the argon ions. These films have also been additionally characterized by Fourier transform infrared (FTIR) absorption spectroscopy. Spectra have been obtained in the range of $400-4000 \mathrm{~cm}^{-1}$. Infrared $\mathrm{C}-\mathrm{H}$ vibrations from 2850 to $3100 \mathrm{~cm}^{-1}$ were observed. Dischler, Bubenzer, and Koidl ${ }^{19}$ assigned individual absorption peaks for $a$-C:H films (Table II). The $3300 \mathrm{~cm}^{-1}$ peak ascribed to $-\mathrm{C} \equiv \mathrm{C}-$ was not observed. The formation of $s p^{1}$ bonded carbon is unlikely using the plasma beam source. The obtained spectra have been fitted with five Gaussians allowing all parameters to vary except the positions which were held in intervals of $5 \mathrm{~cm}^{-1}$ around those assigned by Dischler (Table II). The sixth absorption that has been assigned at $3045 \mathrm{~cm}^{-1}$ was not considered because the intensity of the absorption of wavelengths over $3000 \mathrm{~cm}^{-1}$ was too low to separate two lines. The observed lines are $\mathrm{C}-\mathrm{H}$ bonding, therefore the spectra provides only information on the hydrogen bonding to carbon and not pure $\mathrm{C}-\mathrm{C}$ bonds. Tamor and $\mathrm{Wu}^{20}$ found that their $a-\mathrm{C}: \mathrm{H}$ films contained large amounts of unprotonated $s p^{2}$-bonds which are not visible to infrared spectroscopy. Hydrogen seems to preferentially bond to $s p^{3}$ coordinated carbon. Measurements of Grill and Patel ${ }^{21}$ support this idea. Therefore, the analysis of intrared (IR) data to obtain the $s p^{3} / s p^{2}$ ratio of the films is strictly speaking, not suitable. In addition, a quantitative analysis would contain an error due to different oscillator strengths of the lines. Nevertheless, if equal oscillator strengths are assumed, the proportion of the $s p^{3}$ hybridized lines stays nearly constant at $75 \%$ of the total absorption.

The $s p^{3}$ content for an $\mathrm{Ar} / \mathrm{C}_{2} \mathrm{H}_{2}$ ratio of 3:1 as determined by $K$ edge EELS spectroscopy is presented in Fig. 2 . The $s p^{3}$ content shows a small maximum at $200 \mathrm{eV}$. The average coordination number of the films is shown in Fig. 3 and shows two maxima at about $100 \mathrm{eV}$ (which belongs to the very low hydrogen content due to the Ar bombardment) and a maximum at $200 \mathrm{eV}$. To get more information on the hydrogen bonding in the films thermal desorption mass spectroscopy (TDMS) was performed. For this purpose the films

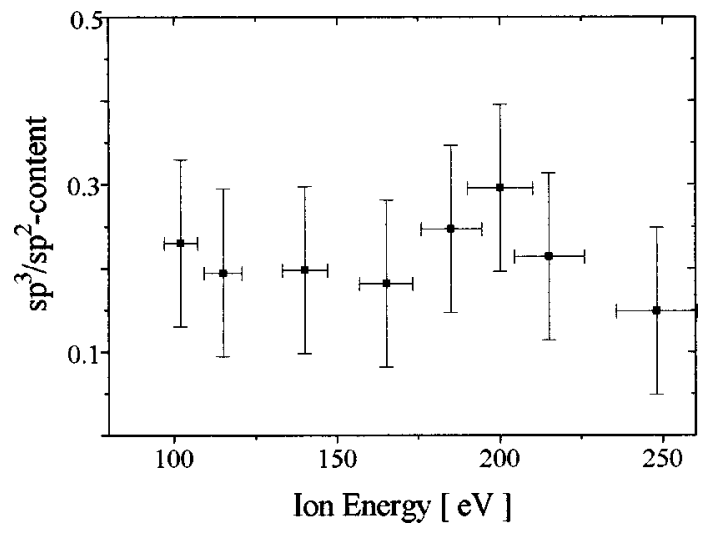

FIG. 2. $s p^{3} / s p^{2}$ content of plasma beam deposited $a$-C:H films with working gas mixture containing both acetylene and argon. $\mathrm{Ar} / \mathrm{C}_{2} \mathrm{H}_{2}=3: 1$ (ם).

have been heated up to $1120 \mathrm{~K}$ using a heating rate of 20 $\mathrm{K} / \mathrm{min}$. Mainly $\mathrm{H}_{2}$ and $\mathrm{CH}_{4}$ were found. These molecules are the most probable forms in which hydrogen can desorp from the surface (assuming that most molecules desorb directly from the surface). Radical or ionic species will desorb with a lower probability from the surface because of their higher reactivity. More complex hydrocarbons may also desorb from the surface, but are also less probable since a larger number of surface bonds will need to be broken. We also find $\mathrm{CH}_{3}$ and $\mathrm{CH}_{2}$ in our mass spectra, but these findings are due to cracking patterns of the $\mathrm{CH}_{4}$ molecules (see Fig. 4). The Ar desorption from the $a-\mathrm{C}: \mathrm{H}$ film starts earlier than the $\mathrm{H}_{2}$ or $\mathrm{CH}_{4}$ desorption. There is a low step at $650 \mathrm{~K}$ and a larger step at around $850 \mathrm{~K}$. The reason for this behavior is the chemical inertness of the Ar atoms. They do not bond to the film, so that as soon as there is an enhanced probability for the Ar to diffuse through the carbon film, the effusion of the Ar will take place. This leads to the assumption that structural changes are made to the $a-\mathrm{C}: \mathrm{H}$ film at temperatures of about $850 \mathrm{~K}$. The effusion of hydrogen starts at a temperature of $870 \mathrm{~K}$ and reaches a maximum at $970 \mathrm{~K}$ for all $a$-C:H films. Principally the hydrogen may exist in the film as unbonded $\mathrm{H}_{2}, \mathrm{CH}_{4}$ molecules, at inner surfaces of the carbon film (voids) or single bonded hydrogen in the

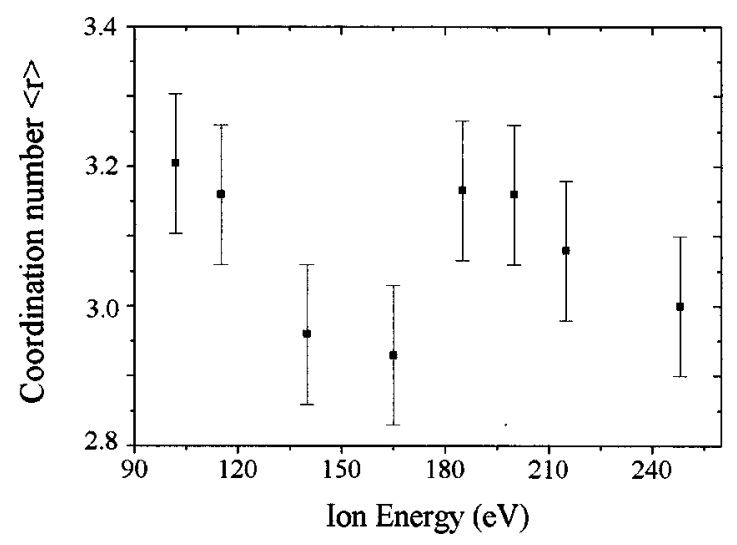

FIG. 3. Medium coordination number of plasma beam deposited $a-\mathrm{C}: \mathrm{H}$ films with working gas mixture containing both acetylene and argon. $\mathrm{Ar} / \mathrm{C}_{2} \mathrm{H}_{2}=3: 1$ (口). 


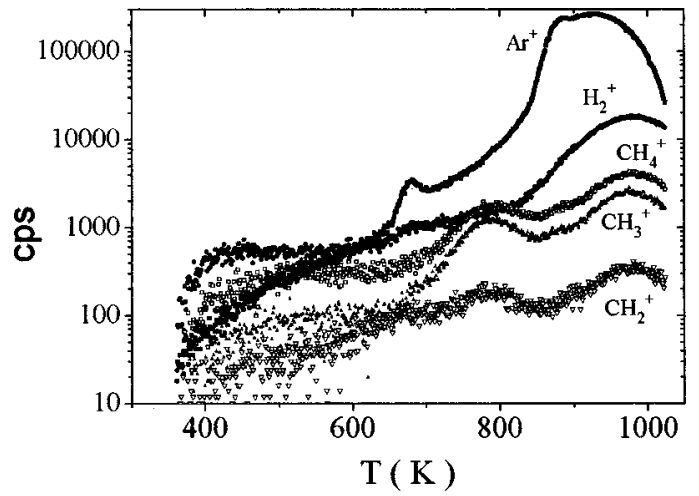

FIG. 4. Thermal desorption spectrum (TDMS) of plasma beam deposited $a$-C:H films with working gas mixture containing both acetylene and argon $\left[\mathrm{Ar} / \mathrm{C}_{2} \mathrm{H}_{2}=3: 1(\mathbf{\square})\right]$ at an ion energy of $140 \mathrm{eV}$.

carbon film (thus mainly $\mathrm{CH}$ groups should exist and less $\mathrm{CH}_{3}$ groups or $\mathrm{CH}_{2}$ groups).

We do not expect a large amount of unbonded hydrogen to exist in the films due to the small atomic diameter of a hydrogen molecule (1.8 $\AA$ ). Since the atomic diameter of $\mathrm{Ar}$ is $2 \AA$, it would be expected that the desorption of hydrogen should start at lower temperatures than the Ar due to diffusion processes. From our measurement this can not be concluded, for unbonded hydrocarbons. The formation of hydrocarbons is less likely than the formation of hydrogen molecules. This means that the hydrogen is likely only to be bonded in small amounts as unbonded hydrocarbons in the $a-\mathrm{C}: \mathrm{H}$ film due to the low atomic hydrogen content. If the hydrogen is bonded at inner surfaces the hydrogen diffusion should be increased if unsaturated carbon sites exist in the neighbourhood. The density of those dangling bonds was measured and amounts to $10^{20}$ dangling bonds $/ \mathrm{cm}^{3} \quad(=1$ $\times 10^{-4} \AA^{3}$ ). The effusion of the hydrogen starts at about $870 \mathrm{~K}$ leading to the assumption that in the deposited $a-\mathrm{C}: \mathrm{H}$ films only small voids can exist. Otherwise, effusion should start at lower temperatures since the dangling bond density is so large. This leads to the assumption that the hydrogen should mainly be bonded to the $a-\mathrm{C}: \mathrm{H}$ film in the form of $\mathrm{C}-\mathrm{H}_{x}$ bonds.

The explanations given also fit the desorption mechanism of methane. The effusion of methan starts at the same temperature as the effusion of hydrogen. The cracking of bonds at the surface of the film leads to the fact that $\mathrm{H}_{2}$ and $\mathrm{CH}_{4}$ are created at the surface. The energy needed to break a $\mathrm{C}-\mathrm{H}$ bond amounts $E_{\mathrm{C}-\mathrm{H}}=4.5 \mathrm{eV} .^{22}$ The energy needed to break a $\mathrm{CH}_{3}$ group from the surface amounts $E_{\mathrm{C}_{-} \mathrm{CH}_{3}}=3 \mathrm{eV}$. If we assume that the formation energy of $\mathrm{H}_{2}$ and $\mathrm{CH}_{4}$ can be compared the energy difference $\Delta E=\Delta E_{\mathrm{C}_{-} \mathrm{CH}_{3}}$ $-\Delta E_{\mathrm{C}-\mathrm{H}}=1.5 \mathrm{eV}$, showing that the formation of methane should be more probable than the formation of hydrogen. This also means that as long $\mathrm{CH}_{3}$ groups exist at the surface the effusion of methane is more likely.

The stress values of the $a-\mathrm{C}: \mathrm{H}$ films is shown in Fig. 5 as a function of the ion energy. For both flux series two maxima are revealed at about 100 and $200 \mathrm{eV}$, also suggesting that two different growth processes occur as a function of ion energy. Films deposited at higher energy give maximum

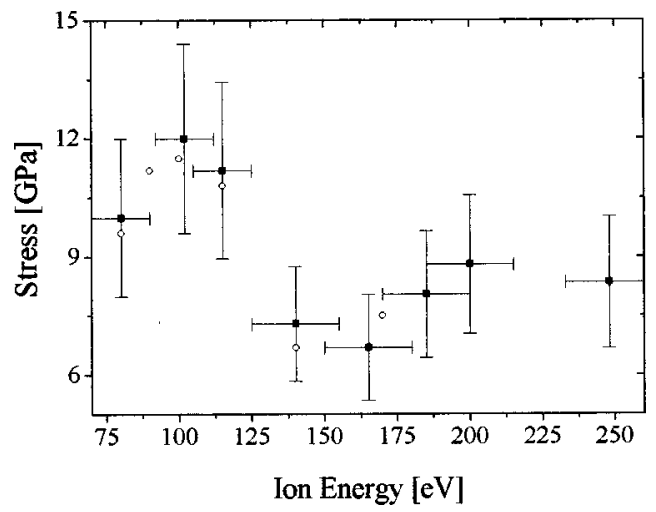

FIG. 5. Stress of plasma beam deposited $a-\mathrm{C}: \mathrm{H}$ films with working gas mixture containing both acetylene and argon. $\mathrm{Ar} / \mathrm{C}_{2} \mathrm{H}_{2}=3: 1(\boldsymbol{\square}), \mathrm{Ar} / \mathrm{C}_{2} \mathrm{H}_{2}$ $=6: 1(\bigcirc)$.

stress values of $8.8 \mathrm{GPa}$ and a maximum optical gap [Fig. 6(a) $]$ of $E_{04}=3.1 \mathrm{eV}$ comparable to films deposited by Weiler et $a l^{13}$ with pure acetylene as the working gas. Density and $s p^{3}$ content analysis reveals that the additional $\mathrm{Ar}$

(a)

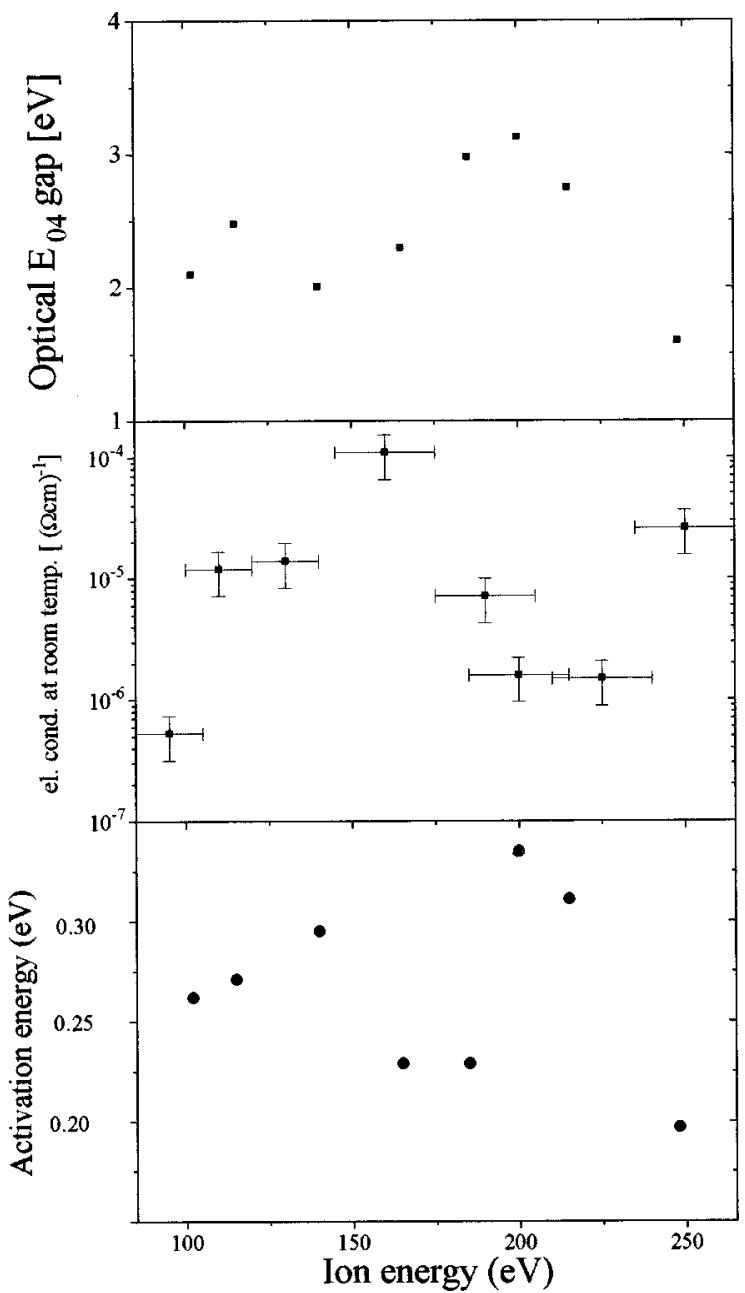

FIG. 6. (a) Optical $E_{04}$ gap vs ion energy of plasma beam deposited $a-\mathrm{C}: \mathrm{H}$ films with working gas mixture containing both acetylene and argon. (b) Electrical conductivity vs ion energy of plasma beam deposited $a-\mathrm{C}: \mathrm{H}$ films with working gas mixture containing both acerylene and argon. $\mathrm{Ar} / \mathrm{C}_{2} \mathrm{H}_{2}$ $=3: 1$ (ם) (c) electrical activation energy vs ion energy of plasma beam deposited $a-\mathrm{C}: \mathrm{H}$ films with working gas mixture containing both acetylene and argon. $\mathrm{Ar} / \mathrm{C}_{2} \mathrm{H}_{2}=3: 1$ (ם). 
bombardment during deposition (compared to those films deposited with pure acetylene as working gas) may lead to a decrease in density in the films due to relaxation processes triggered by the incoming energetic Ar. The second maximum at $100 \mathrm{eV}$ ion energy reveals higher stress values of 11 $\mathrm{GPa}$ and a optical gap $E_{04}$ of $2.5 \mathrm{eV}$. The maximum at lower energy can not be found with pure acetylene. Therefore, it must be initiated by the Ar ions. Schwan et al. ${ }^{23}$ have found a maximum density in $a$-C films for the knock-on subplantation by Ar bombardment at about $100 \mathrm{eV}$ which is similar to the peak value of stress found in the study. As in the case of Schwan et al. ${ }^{23}$ the optimum densification of the $a-\mathrm{C}: \mathrm{H}$ films deposited by a $\mathrm{Ar} / \mathrm{C}_{2} \mathrm{H}_{2}$ working gas was found to vary with the ratio of $\mathrm{Ar}^{+}$ions to neutral carbon atoms. It is likely to assume that the incoming $\mathrm{Ar}^{+}$ions may lead to analogous processes regardless of deposition environment. The plasma beam source provides therefore a chance to compare the direct subplantation process with the knock-on process.

The loss of hydrogen at ion energies around $100 \mathrm{eV}$ is accompanied by a maximum in stress, but is not related to any major change in infrared absorption. One possible process that explains these measurements could be a stress induced elimination of hydrogen. The internal stress can be assumed as due to disorder in the lattice due to bond mismatch. For a single atom the binding energy is diminished by the mismatch, so the strength of bond is weakened by the amount of local disorder energy. The internal stress corresponds to an average disorder energy per C-atom. If this disorder energy is high enough, as indicated by the stress exceeding a threshold, a change in bond configuration could gain energy and therefore become possible. Pompe et al. ${ }^{24}$ and McKenzie et al. ${ }^{8}$ developed the idea of such a phase transition for the formation of large amounts of $s p^{3}$ bonds when stress values above a threshold are present: McKenzie et $a l^{8}{ }^{8}$ gives a threshold of $1.46 \mathrm{GPa}$ while Schwan et al. $^{23}$ found a transition above $14 \mathrm{GPa}$ Beside $s p^{3} \mathrm{C}-\mathrm{C}$ and $s p^{2}$ $\mathrm{C}-\mathrm{C}$ bonds, there are $\mathrm{C}-\mathrm{H}$ bonds in hydrogenated films too. Assuming that the stress would invoke a transition at local sites in the films, stress values above a threshold at 10-12 $\mathrm{GPa}$, according to the observed data, could force neighboring $\mathrm{C}-\mathrm{H}$ bonds to be eliminated by forming $\mathrm{C}-\mathrm{C}$ and $\mathrm{H}-\mathrm{H}$ bonds.

The existence of aromatic structures was predicted in earlier theories of the structure of $a-\mathrm{C}: \mathrm{H}$ (Ref. 25) due bond energy savings over simple aliphatic (olefinic) bonding. Recently, Robertson ${ }^{26}$ showed that the disorder energy of ion beam deposited carbon-being in the order of $0.3 \mathrm{eV}$ in amorphous carbon-could exceed the energy gain of fusing of three pairs of $\pi$ electrons to a benzene like ring. Aromatic structures gain energetic preference because of the overlap of wave functions for $\pi$ orbitals delocalizes the participating electrons. If an ion impact during deposition displaces one of the ring atoms, the delocalization of the $\pi$ electrons is disrupted and the energy gain is lost. So the region becoming nonaromatic is far larger than the initial displacement. Therefore, intense ion bombardment could provide an explanation for the absence of aromatic bonds. This would lead to the observed infrared spectrum with extremely low aromatic carbon absorption lines and provides an explanation for the high optical gap. ESR measurements revealed electron spin densities between $6 \times 10^{19}$ and $1.4 \times 10^{20} \mathrm{~cm}^{-3}$.

There is a slight dependence of spin density on hydrogen content, where the highest spin density was found at the lowest hydrogen content. This leads to the assumption that the structure of the PBS deposited carbon films is different to PECVD films. Most carbon films with low hydrogen content have spin densities above $10^{20} \mathrm{~cm}^{-3} \cdot{ }^{20,27,28}$ Hydrogen can reduce the spin density of carbon films down to $10^{18} \mathrm{~cm}^{-3} \cdot{ }^{27}$ On the other hand reducing the hydrogen content should lead to an increased spin density. Taking the dramatic reduction in the hydrogen content in these films a sharply increased number of defects should be obtained in the films deposited at an ion energy of $100 \mathrm{eV}$. Electrical conductivity at room temperature $(297 \mathrm{~K})$ varied over three decades between 5 $\times 10^{-7}$ and $1 \times 10^{-4} \Omega^{-1} \mathrm{~cm}^{-1}$ revealing two maxima at $100 \mathrm{eV}$ and near $200 \mathrm{eV}$ [see Fig. 6(b)]. For amorphous carbon films two possible processes are suggested as the dominant current conduction mechanism, first, a thermally activated process where the conductivity $\sigma(T)$ depends on $\exp (-k T)^{-1}$ or second, a variable range hopping process near the Fermi level $E_{F}$ where there is a $\exp (k T)^{-1 / 4}$ dependence on $\sigma(T) .{ }^{29}$ Conductivity vs reciprocal temperature studies were used to obtain the activation energy $E_{a}$ of the films [Fig. 6(c)]. If it is assumed that thermally activated electronic conduction occurs, then $\sigma(T)=\sigma_{0} \exp (-E a / k T)$ provides the activation energy $E_{a}$ with the values shown in Fig 6(c) obtained to a linear fit in the range $-70-300{ }^{\circ} \mathrm{C}$. The data reveal two maxima at 100 and $200 \mathrm{eV}$ corresponding to that found for the energy gap. The activation energy is an average energy that an electron needs to participate in the conduction process. A change in the activation energy is likely to be either accompanied by a change in the optical gap or a movement of the Fermi level. In the current system, for undoped PBS $a$-C films, since the activation energy change is small it is likely that the variation observed in the range $0.2-0.3 \mathrm{eV}$ is due to carrier activation from the valence band to the $p$-type structured defect present in the $a-\mathrm{C}$ network which has been reported both experimentally ${ }^{30}$ and theoretically. ${ }^{31}$ The conduction process in $a-\mathrm{C}$ will have a strong dependence on the structure of the film. This is illustrated by the fact that the conductivity at room temperature of the deposited films varies over two decades despite $E_{a}$ being apparently constant. To get more information on the conduction process and thereby the electronic density of states nitrogen is added as a fed gas.

\section{B. Doped a-C:H films}

The $a-\mathrm{C}: \mathrm{N}: \mathrm{H}$ films have been deposited at $100 \mathrm{eV}$ ion energy at an $\mathrm{Ar} / \mathrm{C}_{2} \mathrm{H}_{2}$ ratio of three. The composition of the $a-\mathrm{C}: \mathrm{H}:(\mathrm{N})$ films is shown in Fig. 7. With addition of nitrogen into the deposition chamber, the hydrogen content in the films increases from 3 at. \% (without $\mathrm{N}$ ) to 18 at. \% (with $\mathrm{N}$ ) and then decreases very slightly for higher nitrogen fluxes. The $\mathrm{N}$ content in the films rise from about 0 at. $\%$ to about 8 at. $\%$ at a nitrogen flow of $0.75 \mathrm{sccm}$. This is slightly different to findings of Silva et al. ${ }^{32}$ The reason for this might be that in our case the stress plays a role for the hydrogen in- 


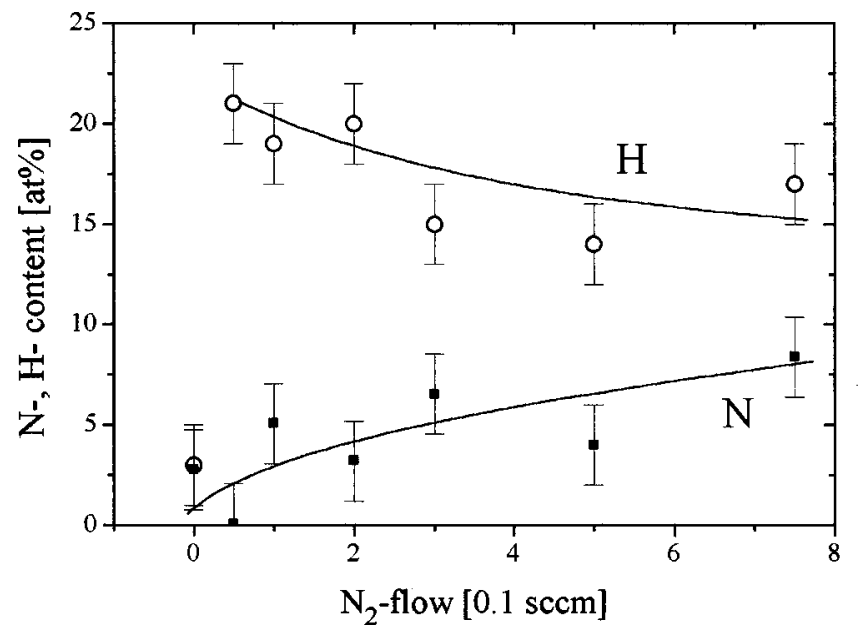

FIG. 7. Elemental analysis of the $a-\mathrm{C}: \mathrm{N}: \mathrm{H}$ films in dependence of the $\mathrm{N}_{2}$ flow left ordinate: $(\triangle) \mathrm{C},(\bigcirc) \mathrm{H}$ : right ordinate $(\boldsymbol{\square}) \mathrm{N}$.

corporation in the $a$ - $\mathrm{C}: \mathrm{H}$ films. As soon as the nitrogen is added the stress in the film decreases below the 10-12 GPa benchmark and the hydrogen content increases to about 20 at. \%. For films with increasing nitrogen content the hydrogen content decreases slightly as observed by Silva et al. ${ }^{32}$

The IR absorption coefficient of the infrared active $\mathrm{N}=\mathrm{C}=\mathrm{N}$ and $\mathrm{C} \equiv \mathrm{N}$ modes are shown in Fig. 8, together with the IR absorption coefficients of the $\mathrm{N}-\mathrm{H}$ and $\mathrm{C}-\mathrm{H}$ modes. The $\mathrm{C}_{2} \mathrm{H}_{2}$ molecules in the plasma dissociate when they impinge on the film surface. As a consequence, hydrogen is released from the $\mathrm{C}_{2} \mathrm{H}_{2}$ bonds to the nitrogen because the $\mathrm{NH}$ bonding energy $(3.7 \mathrm{eV})$ is higher than the $\mathrm{CH}$ bonding energy $(3.5 \mathrm{eV})$. This explains the observed IR absorption coefficients for the increase in the $\mathrm{NH}$ bonds and the decrease in the $\mathrm{CH}$ bonds. The IR absorption coefficient for the wave numbers between 1000 and $1700 \mathrm{~cm}^{-1}$ increases strongly especially with the highest $\mathrm{N}$ incorporation (Fig. 9). A comparison of our IR data to our Raman measurements for the $a-\mathrm{C}: \mathrm{H}:(\mathrm{N})$ films reveal that the increase in the IR absorption coefficient in this wave number region cannot be explained purely by breaking of the symmetry of the Raman active $E_{2 G_{2}}$ mode as Kaufman, Metin, and Saperstein

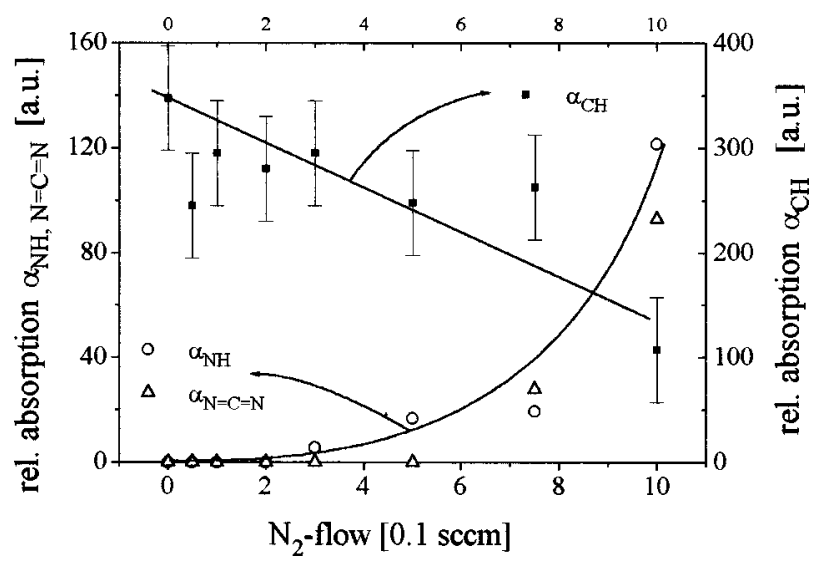

FIG. 8. IR absorption coefficient of the (ם) $\mathrm{CH}$ bonds $\left(2850-3100 \mathrm{~cm}^{-1}\right)$, (O) $\mathrm{NH}$ bonds $\left(3200-3400 \mathrm{~cm}^{-1}\right)$ and $(\triangle) \mathrm{N}=\mathrm{C}=\mathrm{N}$ or $\mathrm{C} \equiv \mathrm{N}$ bonds $\left(2200-2400 \mathrm{~cm}^{-1}\right)$.

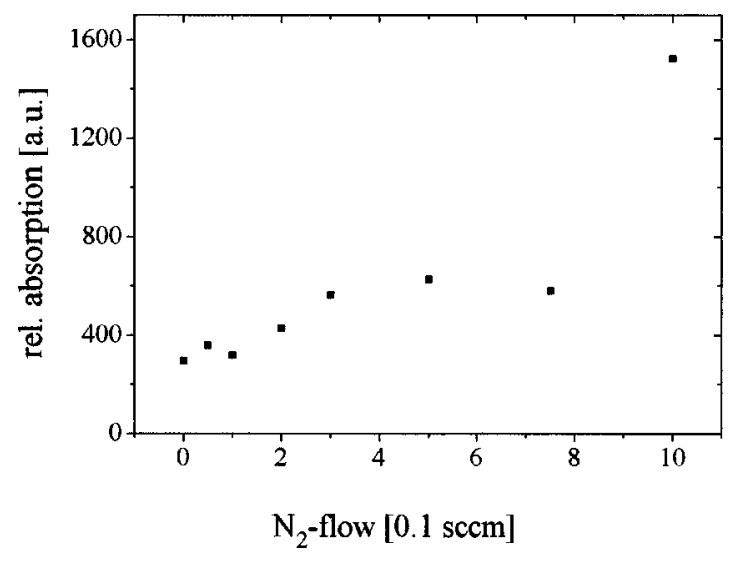

FIG. 9. IR absorption coefficient in the range $1000-1700 \mathrm{~cm}^{-1}$.

discussed. ${ }^{33}$ Our measurements show that the " $G$ peak" of the Raman data and our $G$ peak of the IR data have differences in wave numbers up to $60 \mathrm{~cm}^{-1}$. Further, the Raman " $D$ peak" and IR $D$ peak differ significantly from each other. We explain the strong increase in the IR absorption coefficient in the region between 1000 and $1700 \mathrm{~cm}^{-1}$ by IR active $\mathrm{C}-\mathrm{N}$ and $\mathrm{C}=\mathrm{N}$ bonds each contributing to the IR activity in that wave number region.

The $E_{04}$ gap vs the nitrogen flow is shown in Fig. 10. Surprisingly, the optical gap shows a maximum of $2.7 \mathrm{eV}$ at a $\mathrm{N}_{2}$ flow of $0.5 \mathrm{sccm}$. This result is in contradiction to findings by other groups concerning $a$ - $\mathrm{C}: \mathrm{H}$ deposited by PECVD. ${ }^{6,7}$ In PECVD deposited $a-\mathrm{C}: \mathrm{H}$, nitrogen incorporation leads to a strong decrease in the optical gap because the aromatic regions in the $a-\mathrm{C}: \mathrm{H}: \mathrm{N}$ films grow in size with increasing $\mathrm{N}$ incorporation. For the $a-\mathrm{C}: \mathrm{H}: \mathrm{N}$ films deposited by the PBS at an ion energy of $105 \mathrm{eV}$, the optical gap first increases and then decreases only at higher $\mathrm{N}_{2}$ flows beyond $0.5 \mathrm{sccm}$. Silva et al $^{32,34-37}$ saw a similar result in their magnetically enhanced plasma deposited $a-\mathrm{C}: \mathrm{H}: \mathrm{N}$ films.

For carbon films deposited by the PBS with concurrent $\mathrm{Ar}$ bombardment it is possible that the model of Robertson ${ }^{1,12}$ based on aromatic clusters needs to be extended in such a manner that the role played by the defects also needs to be incorporated. The Urbach energy vs $\mathrm{N}_{2}$ flow is presented in Fig. 11. It is observed that the Urbach slope remains nearly constant at $270 \mathrm{meV}$ upto a $\mathrm{N}_{2}$ flow of 0.6

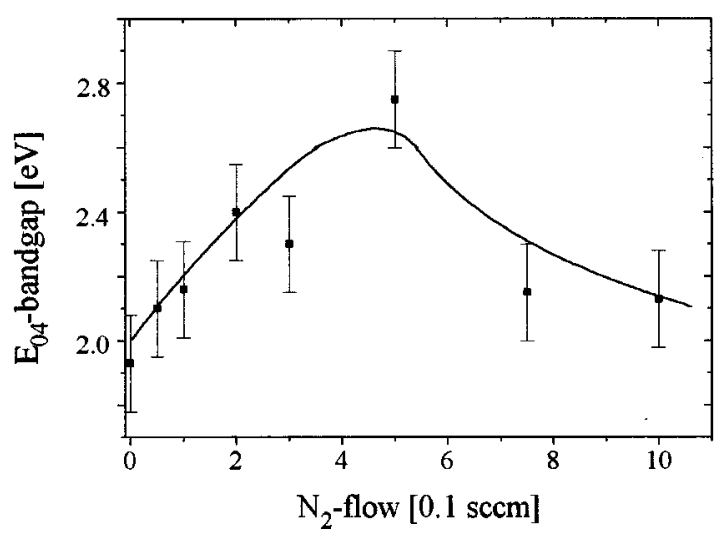

FIG. 10. $E_{04}$ gap in dependence of the $\mathrm{N}_{2}$ flow. 


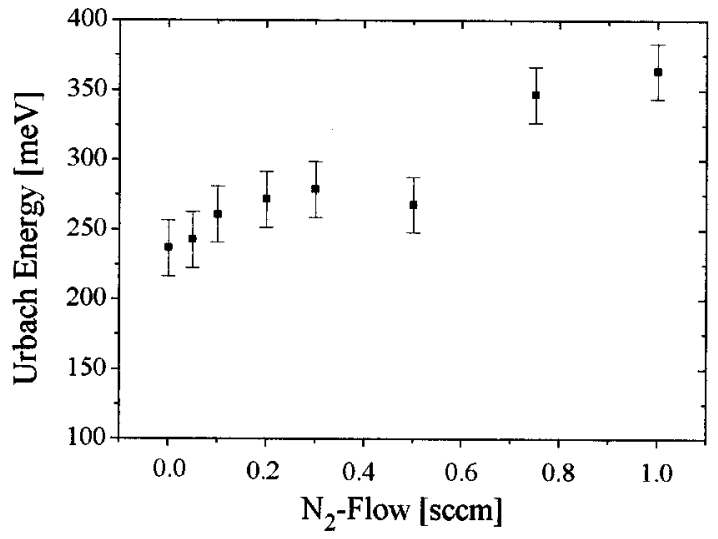

FIG. 11. Urbach energy in dependence of the $\mathrm{N}_{2}$ flow.

sccm which is a typical value for $a-\mathrm{C}$ and $a-\mathrm{C}: \mathrm{H}$ films. This high Urbach energy is consistent with the high defect density of $10^{20}$ defects $/ \mathrm{cm}^{3}$ and also points to the fact that the optical properties may be determined by defect states in the band gap. The Urbach energy becoming larger and close to 350 $\mathrm{meV}$ beyond a $\mathrm{N}_{2}$ flow of $0.6 \mathrm{sccm}$ is consistent with the widening of the tail states giving rise to the decrease in the optical band gap.

Another interesting feature that might give information about the structure is the luminescence properties of the $a$-C:H films. ${ }^{8,9,32}$ In Fig. 12 the position of the luminescence peak is shown vs the $\mathrm{N}_{2}$ flow. Rusli, Amaratunga, and Robertson ${ }^{38}$ proposed that electron hole pairs are strongly localized after photogeneration. Thus the excitation and recombination of electron hole pairs are believed to occur in $\pi$ bonded clusters, as prooved by experimental evidence. Since we use an excitation energy of $2.54 \mathrm{eV}$, it is possible that the luminescence is dominated by excitation to the tail states. This may be the reason why the luminescence peak energy remains approximately constant at $2 \mathrm{eV}$. It is worth noting that many forms of $a-\mathrm{C}$ films with $\mathrm{N}$ incorporation give rise to a PL peak energy of about $2 \mathrm{eV}$. It is possible that this energy is a fundamental property of the $\mathrm{C}-\mathrm{N}$ bond and is observed due to the formation of a carbon-nitrogen alloy with its own unique signature.

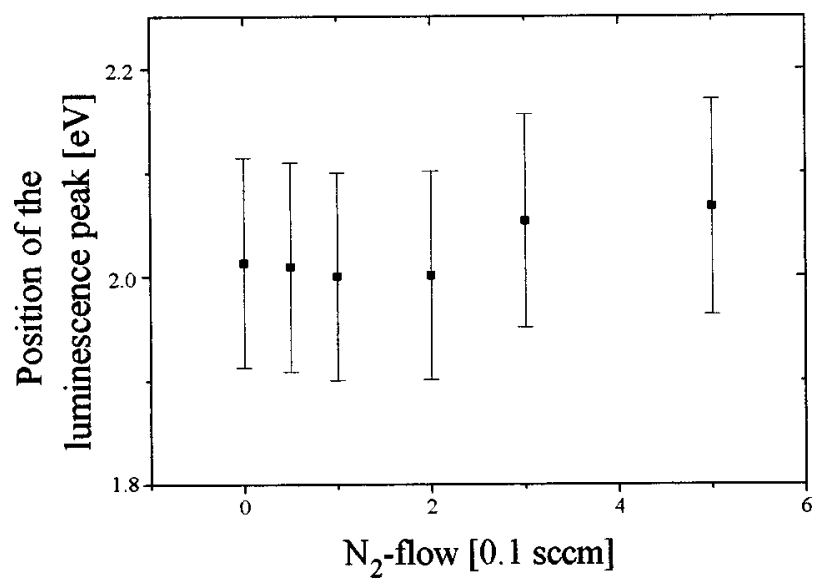

FIG. 12. Luminescence energy vs $\mathrm{N}_{2}$ flow.

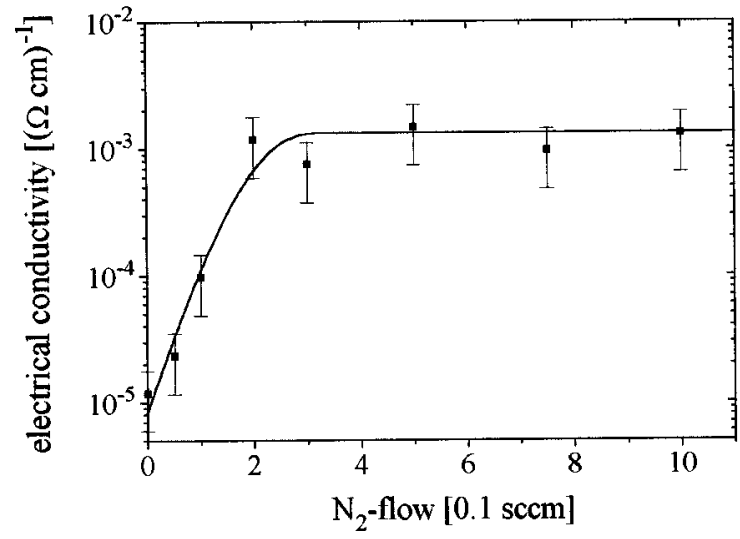

FIG. 13. Electrical conductivity at room temperature vs $\mathrm{N}_{2}$ flow.

The electrical conductivity increases strongly from 1 $\times 10^{-5}(\Omega \mathrm{cm})^{-1}$ at $0 \mathrm{sccm} \mathrm{N} \mathrm{N}_{2}$ up to $3 \times 10^{-3}(\Omega \mathrm{cm})^{-1}$ at $0.3 \mathrm{sccm} \mathrm{N}_{2}$ and then staying constant for all higher $\mathrm{N}_{2}$ flows (Fig. 13). Both the optical gap and electrical conductivity increase simultaneously for low $\mathrm{N}$ incorporation. This is different to nitrogenated $a$-C:H films deposited by conventional PECVD. This fact will be discussed in more detail, but it has to be noted that the structure of $a-\mathrm{C}: \mathrm{H}$ films deposited by the PBS is different to $a-\mathrm{C}: \mathrm{H}$ films deposited by PECVD. In Fig. 14 the electrical conductivity vs Tauc gap for $a-\mathrm{C}: \mathrm{H}:(\mathrm{N})$ films is presented for films deposited by PBS and PECVD. ${ }^{7}$ Here, the difference of the physical behavior of the $a-\mathrm{C}: \mathrm{H}: \mathrm{N}$ films deposited by the different methods can be observed more clearly.

Temperature dependent electrical conductivity results show that the electrical conduction is thermally activated, with activation energies (vs $\mathrm{N}_{2}$ flow) shown in Fig. 15. We observe approximately linearly decreasing activation energies from $0.27 \mathrm{eV}\left(0 \mathrm{sccm} \mathrm{N}_{2}\right)$ down to $\left.0.18 \mathrm{eV}(1 \mathrm{sccm} \mathrm{N})_{2}\right)$. This indicates only a slight movement of the Fermi level through the gap while other properties vary significantly. The defect density is of the order of $1 \times 10^{20}$ defects $/ \mathrm{cm}^{3}$ (Fig. 16) and decreases slightly with increase in $\mathrm{N}_{2}$ content. This variation is not large and is expected by the small movement in the Fermi level in $a$ - $\mathrm{Si}$, a defect density of $10^{18}$ defects/

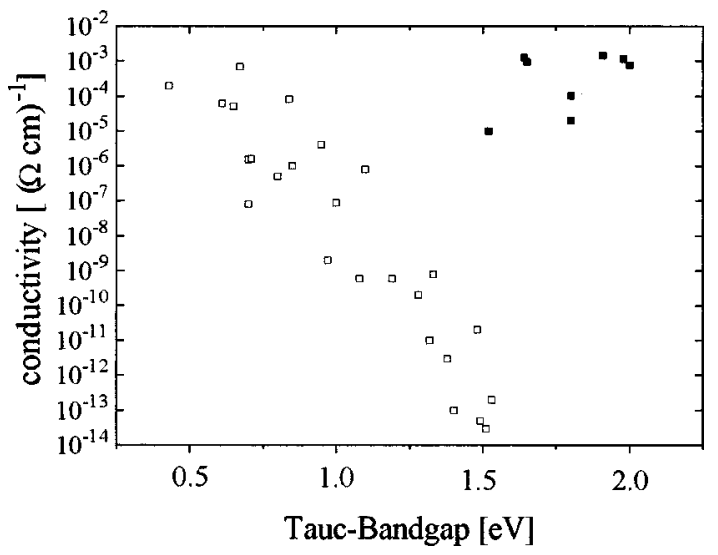

FIG. 14. Electrical conductivity at room temperature vs tauc gap for $a-\mathrm{C}: \mathrm{N}: H$ films deposited by PECVD ( $\square$ ) and PBS (ם) 


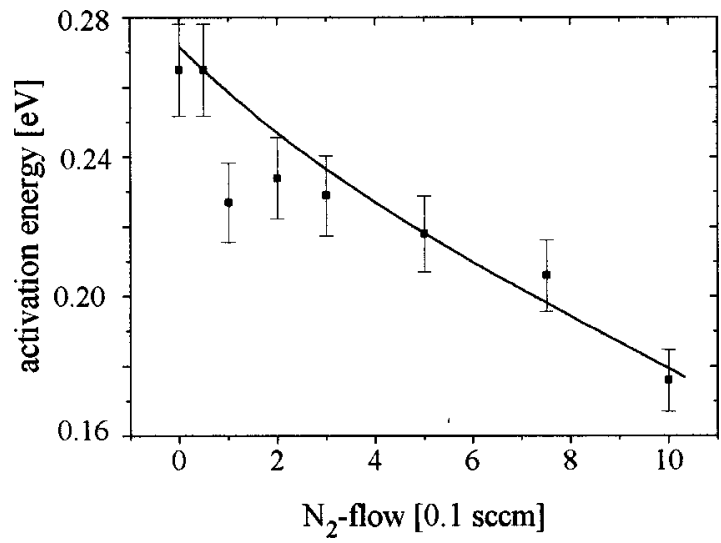

FIG. 15. Activation energies vs $\mathrm{N}_{2}$ flow.

$\mathrm{cm}^{3}$ prevents the films from being doped substitutionally. This means that effects other than doping may account for the decrease in activation energy observed at higher $\mathrm{N}$ contents. The defect density observed has a value comparable to $a-\mathrm{C}$ and $a-\mathrm{C}: \mathrm{H}$ films deposited by other techniques. It is interesting to consider where the defects are located in the band gap. First consider the case where all defects are located at the Fermi level $( \pm 0.1 \mathrm{eV})$ in the middle of the band gap (Davis-Mott model). This would mean the density of states (DOS) at the Fermi level would be in the range of $10^{21}$ $(\mathrm{eV})^{-1} \mathrm{~cm}^{-3}$. But if this were correct for $a-\mathrm{C}: \mathrm{H}$ films, the electrical conductivity of the films should be much higher. This is not observed, so that the DOS of $a-\mathrm{C}$ and $a-\mathrm{C}: \mathrm{H}$ must be a combination of the Cohen-Fritzsche-Oshivinsky (CFO) model and the Davis-Mott model where the defects are distributed between tail states appended to extended states as well as at the middle of the band gap, as shown by Silva and Amaratunga ${ }^{37}$ for $a-\mathrm{C}: \mathrm{H}$ films.

The half width of the ESR signal is approximately $2 \mathrm{G}$ indicating that exchange narrowing does occur $(\mathrm{H}$ content is below 20 at. $\%$ and consequently does not influence the ESR width). The low value of the ESR half width indicates that the exchange frequency must be high which is indicative that the electrons are not strongly localized. The ESR findings are supported by PDS measurements. PDS shows that the optical absorption coefficient decreases only slightly below $10^{4} \mathrm{~cm}^{-1}$ for photon energies below $2 \mathrm{eV}$ (Fig. 17). This can

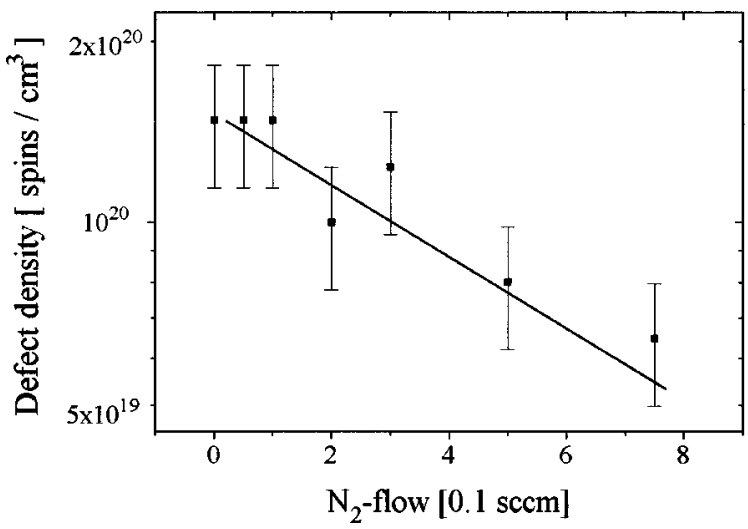

FIG. 16. Defect density vs $\mathrm{N}_{2}$ flow.

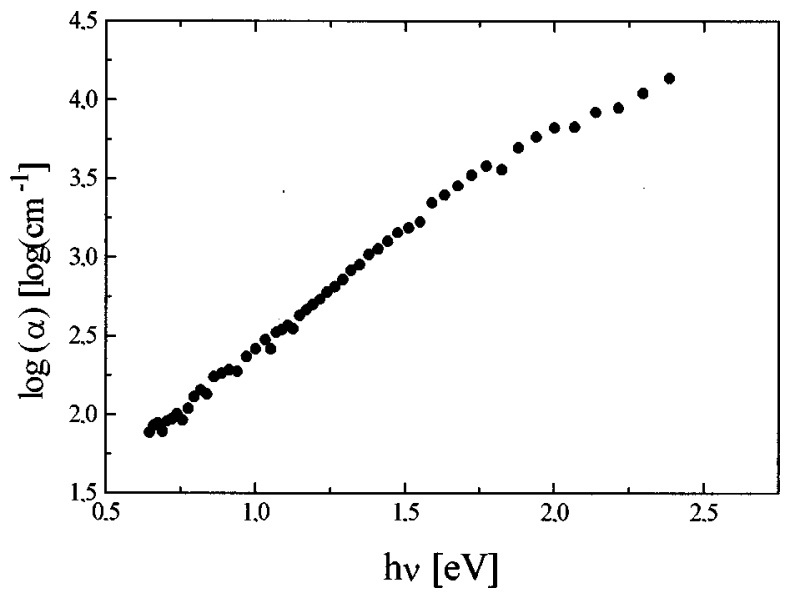

FIG. 17. PDS spectrum of a sample prepared at an ion energy of $105 \mathrm{eV}$ and a $\mathrm{N}_{2}$ flow of $0.3 \mathrm{sccm}$ which has a $E_{04}$ gap of $2.8 \mathrm{eV}$.

only be explained if the DOS in the gap diminish slightly at the valence band edge. Otherwise, there would be a strong decrease in the absorption coefficient as in the case of $a-\mathrm{Si}: \mathrm{H}$ having an Urbach energy of the order of $50 \mathrm{meV}$. Here, in the case of $a-\mathrm{C}: \mathrm{H}: \mathrm{N}$, the Urbach energy remains nearly constant for all $\mathrm{N}_{2}$ flows at a value of $250 \mathrm{meV}$, which is comparable to values normally observed in the literature. ${ }^{34}$

The mobility of the charge carriers (which are assumed to be electrons for the nitrogenated samples) is presented in Fig. 18 as determined by Hall measurements. Prior to these measurements, Hall measurements were conducted on Bdoped polycrystalline diamond films prepared by CVD. ${ }^{18}$ Both the mobility and carrier type obtained were in agreement to other published literature. In the case of undoped $a-\mathrm{C}: \mathrm{H}: \mathrm{N}$ films a Hall mobility could not be measured. There is a strong increase in the mobility with $\mathrm{N}_{2}$ flow reaching a maximum value of about $10 \mathrm{~cm}^{2} / \mathrm{Vs}$ at a nitrogen flow of $0.75 \mathrm{sccm}$. Fig. 19(a) presents the Hall-Resistance and Fig. 19(b) a comparison of the electrical resistance of the films measured by the van-der Pauw method (measured during the Hall measurements) and electrical conductivity measured by another method (between two parallel electrical contacts at a distance of $0.3 \mathrm{~mm}$, a voltage of $100 \mathrm{~V}$ was applied and the

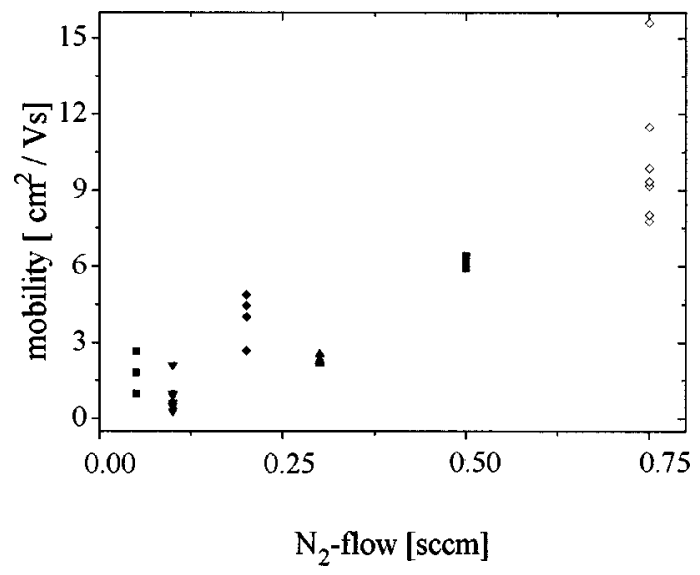

FIG. 18. Mobility of the charge carriers as determined by Hall measurements. 
(a)

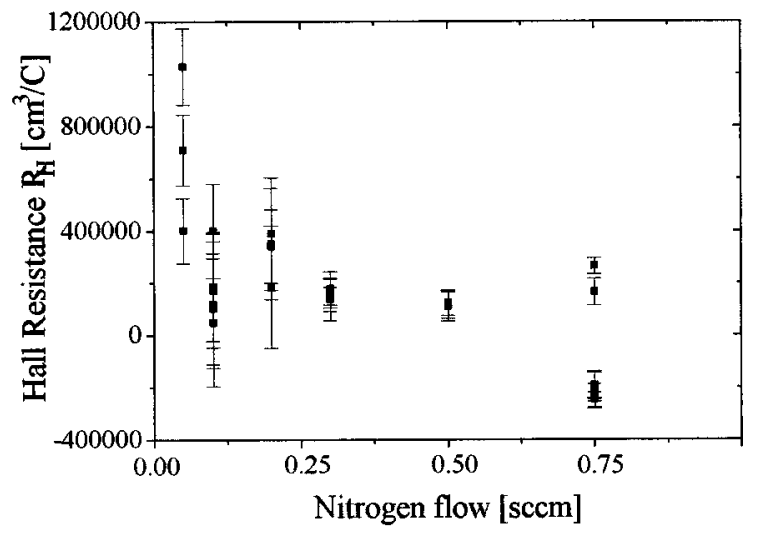

(b)

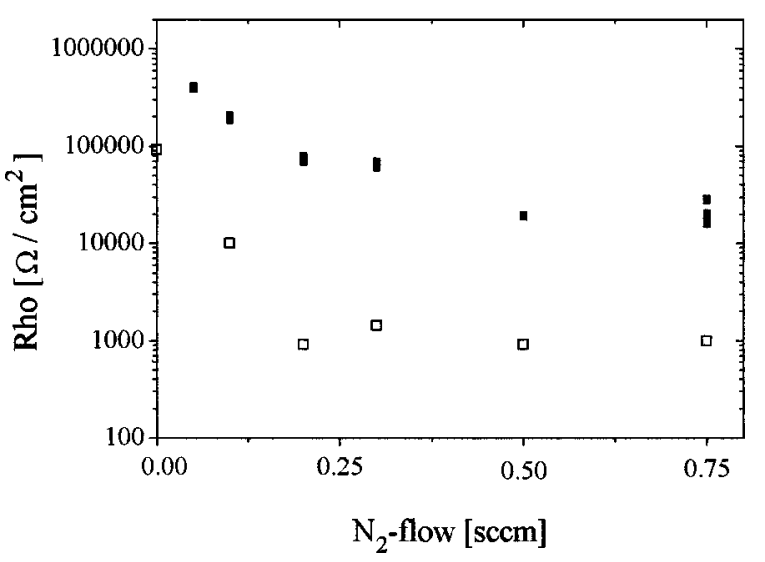

FIG. 19. (a) Hall resistance in dependence of Nitrogen flow. (b) Comparison of electrical resistance measured by van der Pauw (ם) and two parallel contacts $(\square)$

electrical current measured). The mobility of the doped carbon films gives results comparable to the best $a$-Si:H films. Original data is presented due to the surprisingly high mobility calculated.

The behavior of the mobility may be explained if the environment at which the electrons are located changes to be aromatic ring structures or conjugated carbon chains which grow in size and as a consequence become more delocalized as the nitrogen content increases. ${ }^{7}$ As a consequence it is possible that the mobility of the electrons increase. According to the Robertson model, the optical gap is inversely related to to the aromatic cluster size ${ }^{39}$ and therefore a collapse in the optical gap for high $\mathrm{N}$ contents is expected. This is not observed in our results. So the possibility is that large conjugated carbon chains delocalize the electron distribution. The conjugated carbon chains and to a lesser degree aromatic bondings may be the reason why the electrical behaviour of $a-\mathrm{C}: \mathrm{H}$ is so completely different compared to $a-\mathrm{Si}: \mathrm{H}$ (high electrical mobility and high defect density are not possible in $a$-Si:H). The increase, and, not decrease, in the optical gap with $\mathrm{N}_{2}$ flows up to $0.3 \mathrm{sccm}$ lends further proof that our films do not follow the Robertson model. This may be due to the large number of defect states in the gap partly determining the optical and electrical properties of $a-\mathrm{C}$ films and a significant proportion of conjugated carbon being present.

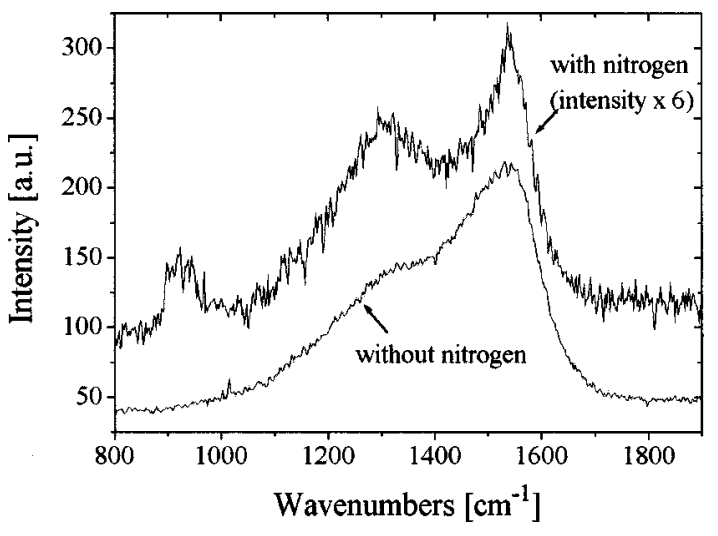

FIG. 20. Raman spectra of pure $a-\mathrm{C}: \mathrm{H}$ film deposited by PBS and of a nitrogenated $a-\mathrm{C}: \mathrm{H}$ film deposited by PBS. The peak at $900 \mathrm{~cm}^{-1}$ can be assigned to silicon. The peak at $1350 \mathrm{~cm}^{-1}$ is the so called $D$ peak. The peak at $1600 \mathrm{~cm}^{-1}$ is the so called $G$ peak

Electronic doping effect in the films may also have a significant influence on the electronic and optical properties of the films.

\section{DISCUSSION}

The $a-\mathrm{C}: \mathrm{H}$ films deposited by the PBS show a large optical gap (above $2 \mathrm{eV}$ ) compared to $a-\mathrm{C}: \mathrm{H}$ films deposited by PECVD although having only a slightly higher $s p^{3}$ content (about 30\%). Raman investigation of undoped $a-\mathrm{C}: \mathrm{H}$ films grown by the PBS show only a small $D$ peak at $1350 \mathrm{~cm}^{-1}$ (Fig. 20). We will briefly discuss two possibilities which may explain the observed data. The first possibility would be if there exist a small number of extended (aromatic) ring structures in the PBS deposited a-C:H. This means that the aromatic $\pi$ bonds only have a minor contribution to the DOS in the undoped films and the majority of $\pi$ bonds are olefinic in nature. In the case of the nitrogenated $a$-C:H films the intensity ratio of the $D$ peak/ $G$ peak (Fig. 20 ) is higher and the G linewidth is smaller than in the case of nonnitrogenated films. This shows that some aromatic rings are formed in the films due to nitrogenation. ${ }^{7}$ It is proposed that Robertson's model ${ }^{39}$ on the dependence of the band gap on the aromatic cluster size should be modified to incorporate defect states (about $10^{20}$ defects $/ \mathrm{cm}^{3}$ in our films) which are situated at the $\pi$ and $\pi^{*}$ band tails in the mobility gap as well as close to the Fermi level. The defect states may contribute significantly to the Urbach tail and consequently to the optical gap and electrical mobility gap, especially in $a-\mathrm{C}: \mathrm{H}$ films deposited by techniques such as PBS where there is a low aromatic content (even though small percentage of clustering will be introduced with nitrogenation). In most PECVD deposited $a-\mathrm{C}: \mathrm{H}$ it should be noted that the $\pi_{\text {aromatic }}$ states make a strong contribution to the DOS and so the effect of decreasing the defect density in the gap may not play a significant role in the size of the band gap. This is clearly seen by increasing the $\mathrm{N}$ content in the PECVD deposited $a-\mathrm{C}: \mathrm{H}$ where the band gap of the films tends to zero $\mathrm{eV}$ due to the increase in the aromatic ring cluster sizes ${ }^{6,7}$ although the defect density is decreased by two orders of magnitude. 
In the case of the PBS deposited nitrogenated $a-\mathrm{C}: \mathrm{H}$ films no such decrease in the band gap is observed. Only an increase in the gap and a decrease in the ESR density is observed. These results point to the fact that the influence of aromatic clusters in the PBS deposited films is minimal with increasing $\mathrm{N}$ content. Some defect passivation in the tail states may be taking place and giving rise on the increase in the optical gap. Therefore, unlike conventional PECVD deposited films where the aromatic ring cluster sizes control the optical gap of the deposited $a-\mathrm{C}: \mathrm{H}$ films, in the PBS films it is the defect states in the gap that control the optical gap and not the aromatic ring clusters.

Another possibility to explain the observed data would be if the $s p^{3}$ content increases with increasing $\mathrm{N}$ content. The nitrogen could act in this case as a weak donor. The higher the donor density the higher the electrical conductivity. We did not observe a decrease in the electrical conductivity followed by an increase as in the case of a compensated semiconductor in which the nitrogen is a donor. ${ }^{32}$ The $\mathrm{C}_{2} \mathrm{H}_{2}$ gas may contain upto $0.5 \% \mathrm{~N}_{2}$ due to the industrial process in the forming of the gas. This means that all our $a-\mathrm{C}: \mathrm{H}$ films may contain small amounts of nitrogen. As a result we may not find that the conduction first decreases with increasing nitrogen content, as the $p$-type structural defect may already have been compensated for in the DOS.

According to Robertson, ${ }^{39} s p^{2}$ configurated aromatic clusters or defects as found in PBS deposited nitrogenated $a-\mathrm{C}: \mathrm{H}$ films (Raman) although not significant in controlling the optical band gap, gives rise to a subband gap of about 0.6 $\mathrm{eV}$. These subband gap states associated with the $\pi$ and $\pi^{*}$ bands obtained using a tight binding model were experimentally observed by Silva and Amaratunga ${ }^{37}$ using a space charge limited current analysis. According to the DOS proposed by Silva and Amaratunga, defect states give rise to localized gap states situated at the middle of the band gap for undoped $a$-C:H films with $\pi$ and $\pi^{*}$ bands situated $\pm 0.3 \mathrm{eV}$ from this intrinsic Fermi level in accordance to the Davis Mott model for the DOS in an amorphous material.

The activation energy shown in Fig. 15 shows the expected $0.3 \mathrm{eV}$ energy for undoped $a-\mathrm{C}: \mathrm{H}$. This could be a result of carriers being thermally activated from the intrinsic Fermi level at mid gap to either of the $\pi$ or $\pi^{*}$ appended states situated $\pm 0.3 \mathrm{eV}$ from the Fermi level. If we now assume that some of the incorporated $\mathrm{N}$ in our films create a $\pi^{*} \mathrm{~N}$ state, situated below the $\pi^{*} \mathrm{C}$ state, ${ }^{36}$ then it is expected that some localized defects in the $a-\mathrm{C}: \mathrm{H}$ will be passivated by the addition of $\mathrm{N}$ and an additional $n$-type dopant state is created as a mixed $\mathrm{C}-\mathrm{N} \pi^{*}$ state. ${ }^{35}$ Therefore, any activation energies measured now will result in thermal activation of carriers from the Fermi level to the mixed $\mathrm{C}-\mathrm{N}$ alloy $\pi^{*}$ conduction band. As shown in Fig. 15, values of less than $0.3 \mathrm{eV}$ are recorded up to a minimum of $0.17 \mathrm{eV}$. Hall measurements give carrier mobilities that are comparable to good $a$-Si:H films ${ }^{40}$ with values as high as $10 \mathrm{~cm}^{2} / \mathrm{Vs}$ which indicate extended carrier conduction as opposed to hopping conduction in these films. $\mathrm{Emin}^{41}$ proposed a Hall mobility model based on polaron hopping. In this model the carriers transfer between adjacent sites. The Hall effect results from the interference between different paths between the initial and final state and involves at least three sites. The sign of the Hall coefficient depends on the number of such sites and on the sign of the transfer integral. If there is an odd number of interconnecting sites and they are connected by anti-bonding orbitals, the sign of the Hall coefficient is positive, but bonding or lone pair orbitals give a negative Hall effect. In our case it is impossible to determine the Hall mobility sign for high doping levels. The model requires hopping between nearest neighbour atoms, to preserve the correlation between the wavefunctions and to cause interference effects in the transfer integrals. Such a model would apply to a narrow band gap material or when the mobility edge is at the center of the band, ${ }^{40}$ which is the case for our films. It should be noted that the observed doping effect is very inefficient ${ }^{32}$ and in addition to the creation of a mixed $\mathrm{C}-\mathrm{N} \pi^{*}$ state, the nitrogen may also encourage the creation of aromatic clusters as observed in the Raman results. The weak doping effect is further confirmed by the small decrease in ESR spin density with increasing $\mathrm{N}$ content. This decrease in spin density may have resulted due to the pairing up of defects in the creation of larger clusters of aromatic rings.

\section{SUMMARY}

The electronic properties of nitrogenated $a-\mathrm{C}: \mathrm{H}$ films deposited by the PBS at an ion energy of $105 \mathrm{eV}$ using an $\mathrm{Ar} / \mathrm{C}_{2} \mathrm{H}_{2}=3$ gas composition has been examined. Although some of the results point to a weak doping effect, other results are better explained by an increase of the aromatic clusters in the $a-\mathrm{C}: \mathrm{H}$ films. The initial increase in optical gap taken together with the accompanied increase in electrical conductivity of two orders of magnitude argues for $n$-type doping of $a-\mathrm{C}: \mathrm{H}$. The mobilty of the charge carriers increases to $10 \mathrm{~cm}^{2} / \mathrm{V} \mathrm{s}$ at an $\mathrm{N}_{2}$ flow of $0.75 \mathrm{sccm}$. The Hall mobility of the charge carriers in PBS deposited $a$-C:H films seems to be based on polaron hopping.

\section{ACKNOWLEDGMENTS}

This work was funded by the DFG Project No. Eh23/ 29-1. Further the authors want to thank R. Samlenski, R. Brenn, and $\mathrm{C}$. Jeynes for measuring the $\mathrm{H}$ and $\mathrm{N}$ contents of the carbon films.

${ }^{1}$ B. Meyerson and F. Smith, J. Non-Cryst. Solids 35\&36, 435 (1980).

${ }^{2}$ B. Meyerson and F. Smith, Solid State Commun. 34, 531 (1980).

${ }^{3}$ B. Meyerson and F. Smith, Solid State Commun. 41, 23 (1982).

${ }^{4}$ D. Jones and A. Stewart, Philos. Mag. B 46, 423 (1982).

${ }^{5}$ A. Liu and M. Cohen, Phys. Rev. B 41, 10727 (1990).

${ }^{6}$ O. Amir and R. Kalish, J. Appl. Phys. 70, 4958 (1991).

${ }^{7}$ J. Schwan, W. Dworschak, K. Jung, and H. Ehrhardt, Diamond Relat. Mater. 3, 1034 (1994).

${ }^{8}$ D. McKenzie, D. Muller, and B. Pailthorpe, Phys. Rev. Lett. 67, 773 (1991).

${ }^{9}$ D. McKenzie, D. Muller, E. Kravtchinskaia, D. Segal, D. Cockayne, G. Amaratunga, and R. Silva, Thin Solid Films 206, 198 (1991).

${ }^{10}$ V. Veerasamy, J. Yuan, G. Amaratunga, W. Milne, K. Gilkes, M. Weiler, and L. Brown, Phys. Rev. B 48, 17954 (1993).

${ }^{11}$ C. Ronning, U. Griemeier, M. Gross, H. Hofsäss, R. Downing, and G. Lamaze, Diamond Relat. Mater. 4, 666 (1996).

${ }^{12} \mathrm{H}$. Hofsäss and C. Ronning, in ASM Conference Proceedings of the International Conference on Beam Progressing of Advanced Materials, Cleveland, Ohio, 1996 (unpublished), pp. 29-56. 
${ }^{13}$ M. Weiler, S. Sattel, K. Jung, H. Ehrhardt, V. Veerasamy, and J. Robertson, Appl. Phys. Lett. 64, 2797 (1994).

${ }^{14}$ M. Weiler, S. Sattel, T. Giessen, K. Jung, H. Ehrhardt, V. Veerasamy, and J. Robertson, Phys. Rev. B 53, 1594 (1996).

${ }^{15} \mathrm{C}$. Ronning (private communication).

${ }^{16}$ L. van der Pauw, Philips Res. Rep. 13, 1 (1958).

${ }^{17}$ R. Chwang, B. Smith, and C. Crowell, Solid-State Electron. 1, 217 (1974).

${ }^{18}$ W. Dötter, R. Erz, K. Jung, H. Ehrhardt, M. Grießer, G. Stingeder, G. Grassbauer, in Proceedings of the Eighth CIMTEC (Florence, July 1994) (unpublished), W. Dötter, Ph.D. thesis, Universität Kaiserslautern, 1995.

${ }^{19}$ B. Dischler, A. Bubenzer, and P. Koidl, Solid State Commun. 48, 105 (1983).

${ }^{20}$ M. A. Tamor and C. H. Wu, J. Appl. Phys. 67, 2 (1990); M. A. Tamor, C. H. Wu, R. O. Carter III, and N. E. Lindsay, Appl. Phys. Lett. 55, 1388 (1989).

${ }^{21}$ A. Grill and V. Patel, Appl. Phys. Lett. 60, 2089 (1992).

${ }^{22}$ X. Jiang, W. Beyer, and K. Reichelt, J. Appl. Phys. 68, 1378 (1990).

${ }^{23}$ J. Schwan, S. Ulrich, V. Batori, H. Ehrhardt, and S. Silva, J. Appl. Phys. 80, 440 (1996).

${ }^{24}$ W. Pompe, H. Scheibe, A. Richter, H. Bauer, K. Bewilogua, and C. Weissmantel, Thin Solid Films 144, 77 (1986).

${ }^{25}$ J. Robertson and E. P. O'Reilly, Phys. Rev. B 35, 2946 (1987).

${ }^{26}$ J. Robertson, Pure Appl. Chem. 66, 1789 (1994).

${ }^{27}$ H. Ehrhardt, R. Kleber, A. Krüger, W. Dworschak, K. Jung, I. Mühling, F. Engelke, and H. Metz, Diamond Relat. Mater. 1, 316 (1992).

${ }^{28}$ F. Demichelis, C. F. Pirri, A. Tagliaferro, and D. Dasgupta, Surf. Coat. Technol. 47, 740 (1991).
${ }^{29}$ N. Mott and E. Davis, Electronic Processes in Non-Crystalline Materials (Oxford University Press, Oxford, 1979).

${ }^{30}$ G. A. J. Amaratunga, V. S. Veerasamy, C. A. Davis, W. I. Milne, D. R. McKenzie, J. Yuan, and M. Weiler, J. Non-Cryst. Solids 164, 1119 (1993).

${ }^{31}$ P. Blaudeck, T. Frauenheim, and H. Busman, Phys. Rev. B 49, 11409 (1994).

${ }^{32}$ S. Silva, J. Robertson, G. Amaratunga, B. Rafferty, L. Brown, J. Schwan, D. Franceschini, and G. Mariotto, J. Appl. Phys. 81, 2626 (1997).

${ }^{33}$ J. Kaufman, S. Metin, and D. Saperstein, Phys. Rev. B 39, 13053 (1989).

${ }^{34}$ S. Silva, J. Robertson, Rusli, G. Amaratunga, and J. Schwan, Philos. Mag. B 74, 369 (1996).

${ }^{35}$ S. R. P. Silva and G. Amaratunga, Thin Solid Films 270, 194 (1995).

${ }^{36}$ S. R. P. Silva, B. Rafferty, G. Amaratunga, J. Schwan, D. Franceschini, and L. Brown, Diamond Relat. Mater. 5, 401 (1996).

${ }^{37}$ S. R. P. Silva and G. Amaratunga, Thin Solid Films 253, 146 (1994).

38 Rusli, G. A. J. Amaratunga, and J. Robertson, Phys. Rev. B 53, 16306 (1996).

${ }^{39}$ J. Robertson, Adv. Phys. 35, 317 (1986).

${ }^{40}$ R. A. Street, Hydrogenated Amorphous Silicon, Cambridge Solid State Series, edited by R. W. Cahn (Cambridge University Press, Cambridge, 1991).

${ }^{41}$ D. Emin, in Proceedings of the 7th Conference on Amorphous and Liquid Semiconductors, edited by W. E. Spear (ClCl, Edinburgh, 1986), 249. 